From the American

Board of Family Medicine

Ann Fam Med 2022;20:93-95. https://doi.org/10.1370/afm.2777.

\section{FROM ABFM: BREAKTHROUGHS: WHAT HAS THE NASEM REPORT DONE FOR YOU LATELY?}

Earlier this year, the National Academies of Sciences, Engineering, and Medicine (NASEM) published the first formal consensus study of primary care in 25 years. The consensus committee's report, "Implementing High-Quality Primary Care: Rebuilding the Foundation of Health Care," built on the 1996 Institute of Medicine primary care report. ${ }^{1-3}$ Since the report's launch on May 4, 2021, there have been several efforts to elevate its recommendations as well as some recent breakthroughs in supporting them. Major efforts have included 4 publications in high-impact journals summarizing the report's recommendations; 6 NASEM workshops with high-profile panelists talking about what effective implementation of the recommendations would look like; and dozens of webinars, briefings, and feedback sessions. ${ }^{4-8}$ Here, we report on breakthroughs in 4 major areas and acknowledge a need for champions for report objectives that have not been as successful.

\section{1) A Secretary's Council for Primary Care}

One of the key findings of the report was that there was no federal focus for primary care-no function within Health and Human Services (HHS) whose focus is to support primary care. Primary care delivers more than one-third of all health care visits, more than one-half of all outpatient care, and has the strongest evidence showing a direct link to improving health outcomes and equity, and yet primary care has no federal champion. ${ }^{2}$ This lack of an organized presence within the federal government was acutely apparent during the COVID19 pandemic and largely explains why primary care was given no role in the nation's epidemic plans prior to the pandemic, why primary care had no designated Congressional relief funding, why it received no strategic allocation of protective equipment, and why it was not featured in federal testing or vaccine strategies. The NASEM report calls for a Secretary's Council-an interagency workgroup with the task of coordinating primary care policy and strategy across HHS agencies, the Veteran's Health Administration, and Department of Defense health functions. Other Secretarial interagency work groups, like the Federal Data Council and the more recent Federal Long-Term Recovery and Resilience Plan, both work across HHS agencies to develop shared strategy and policy. ${ }^{9,10}$ The NASEM report also calls for a Federal Advisory Committee to the Secretary's Council so that external stakeholderincluding patients, health professions organizations, payers, health systems - could help shape priorities and strategies.
In October 2021, the Office of the Assistant Secretary for Health announced the formation of an Initiative to Strengthen Primary Health Care with the intention to use the NASEM report as a blueprint. The Initiative is aligning the proposed functions of the council with national health priorities, helping the Secretary and agency leaders understand how the resulting council would help coordinate efforts to make primary care a better solution to shared problems and goals. This planning process will produce a plan for the HHS Secretary for a more permanent interagency workgroup guided by an advisory committee. Early wins could include advising of Medicare or Medicaid on primary care payment models by other agencies that have studied or implemented models that improve access to primary care and health equity. Another early win could be combining the Veteran's Health Administration interest in resolving problems with veteran's care access and the Health Resources and Services Administration charge to help resolve Health Profession Shortage Areas. The creation of this initiative is a major breakthrough and a key to enabling and advancing all other report recommendations. The American College of Physicians calls this a "positive step" but endorses the NASEM committee's position that it have sufficient funding and authority. ${ }^{11}$ This latter admonition is important ${ }_{i}$ the functionality, agency staff assignments, and authority of this new entity will be critical to its success.

\section{2) A National Primary Care Implementation Scorecard}

The report implementation plan also calls for a national scorecard. The report specifically said:

To improve accountability and increase chances of successful implementation, primary care professional societies, employers, consumer groups, and other stakeholders should assemble, and regularly compile and disseminate a "high-quality primary care implementation scorecard," based on the 5 key implementation objectives identified in this report.

This scorecard is not intended to "grade" primary care clinicians and teams, it is intended to assess our nation's progress (or lack thereof) implementing high-quality primary care and to create policy-maker accountability for achieving this goal. Appendix E of the report laid out the principles and specifics of the metrics for each of the report's 16 recommendations and identified existing national source data. The measure principles included:

- Measures should be previously developed and each should track the committee's objectives, either directly or indirectly - The measures should be few, easily understood by the general public, and consistent over time

- Data for the measures must be collected regularly, comprehensively, and reliably for producing assessment at relevant scope or geography; preferably, data will be publicly available and non-proprietary

- Accountable unit - the measure should be available at the national and state levels, so as to engage advocates and policy makers 
An exemplar measure is the percentage of total spend going to primary care from commercial insurance.

The Milbank Memorial Fund is spearheading an effort to organize the publication of the first scorecard. The goal is to give federal and state governments specific targets for primary care policy implementation and a mechanism by which to monitor success. Milbank's leadership is an essential breakthrough to getting this off the ground and we remain hopeful that other philanthropies will join the cause.

\section{3) Primary Care Research Funding}

The NASEM report points out that less than $1 \%$ of federal research investments support primary care research. This significant underfunding of discovery initiatives in the single largest platform for health care means primary care lacks the ability to generate new evidence. In 1996, Congress deemed the Agency for Healthcare Research and Quality (AHRQ) the home for primary care research, but the National Center for Excellence in Primary Care Research that resulted from this legislation has never received dedicated funding. The report calls for prioritization of funding in this AHRQ Center and for the creation of an Office of Primary Care Research at the National Institutes of Health (NIH)_following the example of Office of Emergency Care Research. Primary care currently has no presence at the NIH. Since the launch of the report, AHRQ announced that it would shift $\$ 5$ million into the National Center for Excellence in Primary Care Research and that the 2022 Presidential budget included $\$ 10$ million. ${ }^{12}$ This critical breakthrough is deserving of celebration, but we have a lot more work to do on achieving a level of investment in primary care research to match its presence and importance in our health care system, in keeping populations healthy, and in achieving health equity.

\section{4) Primary Care Payment}

The committee found clear and compelling evidence that aligned payment structures are key to implementing highquality primary care; thus, primary care payment reform is front and center in the report. The report's first objective recommends that all payers move to hybrid payment models with increasing shift to capitated payments that enable robust team-based, comprehensive care. It calls for payments that are not only adjusted for medical complexity, but social complexity too. It calls for prospective investment to support practice transformation, for better valuation of primary care services, and for restoring the Relative Value Scale Update Committee as an advisory function. Lastly, it endorses policies implemented by some states to set a minimum spend threshold for primary care, calling for more states and the federal government to increase investment to $10 \%-12 \%$ of total health care spend. The workshop for the payment objective featured several former HHS leaders and payers who offered support for the Report's direction. ${ }^{13}$ The latest report workshop on October 25, 2021 was a closed-door workshop for payers and health system leaders to discuss the need for all-payer models and for accountability for payments intended for primary care once they flow into health systems. Although there are no specific details regarding breakthroughs in this area yet, there are several efforts underway to advise federal and commercial payers to adopt the NASEM report recommendations.

\section{Key Areas in Need of Champions: Access, Workforce, Digital Health}

The report committee concluded that primary care should be a common good, meaning that anyone who wants a primary care clinical relationship should be able to have it. This would be a fundamental change (1) in assuring access to care and (2) to prioritizing the adequate production of the workforce to provide it. Workshops featuring patients, policy makers, and clinicians were held on both topics and are available to the public. ${ }^{14,15}$ Unfortunately, neither access nor workforce has garnered champions for the objectives:

(1) Ensure that high-quality primary care is available to every individual and family in every community; and (2) Train primary care teams where people live and work. Our hope is that the new HHS Initiative to Strengthen Primary Health Care (described above) will elevate both as functions of its agencies. A champion is also needed to implement the report's digital health recommendations. Digital health was 1 of the 5 main report objectives and was the focus of a NASEM high-profile workshop and a feature article in the Journal of the American Informatics Association. 6,16 This objective calls for designing information technology that serves patients, their families, and the interprofessional primary care team. Digital health was not a focus of the 1996 Institute of Medicine report, given that electronic health records were not widely used at that time. It is surprising that this objective lacks a national champion, given the contribution of electronic health records, interoperability, and functionality to clinician burnout. ${ }^{17}$ The needs of primary care have not been a priority of electronic health records or related policies, and the report outlines important and urgent work to be done in this area.

In conclusion, we hope the primary care community will recognize the importance of these early breakthroughs since the launch of the NASEM report only 6 months ago. The report, thanks to committed champions and receptive policy makers, is already having a tangible impact. The initiative launched by the Office of the Assistant Secretary for Health could lead to important, sustained benefit to primary care and the nation's health and the recent endorsement by the American College of Physicians is a good signal. While early progress has been made, the importance of the long game cannot be overstated, and the efforts that have been started must continue. The report provides a powerful platform to move important initiatives forward, but there is still much more work to be done. Several key objectives within the report pertaining to access, workforce, and digital health remain largely fallow and in need of champions. We hope 
the national family medicine organizations that dedicated the cornerstone funding to launch this important NASEM report will see opportunities to build on their early investment and collaborate on new breakthroughs. ${ }^{2}$

Robert L. Pbillips, Jr, MD, MSPH, The Center for Professionalism \& Value in Health Care, American Board of Family Medicine Foundation, Jennifer DeVoe, Department of Family Medicine, Center for Primary Care Research and Innovation, Oregon Health \& Science University; Alex H. Krist, MD, MPH, Family Medicine and Population Health, Virginia Commonwealtb University

\section{References}

1. Newton WP, Baxley E, Bazemore A, Magill M. From ABFM: implementing a national vision for high quality primary care: next steps. Ann Fam Med. 2021;19(6):564-566. 10.1370/afm.2058

2. National Academies of Sciences, Engineering, and Medicine. Implementing High-Quality Primary Care: Rebuilding the Foundation of Health Care. The National Academies Press; 2021.

3. Donaldson MS, Yordy KD, Lohr KN, Vanselow NA, eds. Primary Care: America's Health in a New Era. National Academy Press; 1996.

4. Phillips RL Jr, McCauley LA, Koller CF. Implementing high-quality primary care: a report from the National Academies of Sciences, Engineering, and Medicine. JAMA. 2021;325(24):2437-2438. 10.1001/jama.2021.7430

5. Grumbach K, Bodenheimer T, Cohen D, Phillips RL, Stange KC, Westfall JM. Revitalizing the U.S. primary care infrastructure. N Engl J Med. 2021;385(13) 1156-1158. 10.1056/NEJMp2109700

6. Krist AH, Phillips R, Leykum L, Olmedo B. Digital health needs for implementing high-quality primary care: recommendations from the National Academies of Sciences, Engineering, and Medicine. J Am Med Inform Assoc. 2021;(ocab190). 10.1093/jamia/ocab190

7. National Academies of Sciences, Engineering, and Medicine. Implementing High-Quality Primary Care: Rebuilding the Foundation of Health Care. NASEM website. Accessed Nov 14, 2021. https://www.nationalacademies.org/ our-work/implementing-high-quality-primary-care

8. Coker TR, Perrin JM. The NASEM report on implementing high-quality primary care-implications for pediatrics. JAMA Pediatr. 2021; 10.1001/ jamapediatrics.2021.4594

9. Well Being Trust. Federal long-term recovery and resilience plan development: mid-course update. Thriving Together Springboard. Published Apr 16, 2021. Accessed Nov 14, 2021. https://thriving.us/federal-long-term-recoveryand-resilience-plan-development-mid-course-update/

10. Assistant Secretary for Planning and Evaluation. Health and Human Services (HHS) Data Council. US Department of Health and Human Services. Published 2021. Accessed Nov 14, 2021. https://aspe.hhs.gov/collaborationscommittees-advisory-groups/hhs-data

11. Erickson SM. ACP, agencies work to prioritize primary care. Published December 2021. Accessed Nov 14, 2021. https://acpinternist.org/archives/ 2021/11/acp-agencies-work-to-prioritize-primary-care.htm

12. Bierman AS, Mcnellis B. Investing in primary care to ensure high-quality care for all Americans. AHRQ Views blog. Published Jul 27, 2021. Accessed Nov 14, 2021. https://www.ahrq.gov/news/blog/ahrqviews/investing-inprimary-care.html

13. National Academies of Sciences. Implementing high-quality primary care webinar series: reforming payment. Published Jun 1, 2021. Accessed Nov 14, 2021. https://www.nationalacademies.org/event/06-01-2021/ implementing-high-quality-primary-care-webinar-series-reforming-payment

14. National Academies of Sciences. Implementing high-quality primary care webinar series: the future workforce. Published Jun 15, 2021. Accessed Nov 14, 2021. https://www.nationalacademies.org/event/06-15-2021/ implementing-high-quality-primary-care-webinar-series-the-future-workforce

15. National Academies of Sciences. Implementing high-quality primary care webinar series: ensuring access. Published Jun 8, 2021. Accessed Nov 14, 2021. https://www.nationalacademies.org/event/06-08-2021/ implementing-high-quality-primary-care-webinar-series-ensuring-access
16. National Academies of Sciences. Implementing high-quality primary care webinar series: digital health. Published June 22, 2021. Accessed Nov 14, 2021. https://www.nationalacademies.org/event/06-22-2021/ implementing-high-quality-primary-care-webinar-series-digital-health

17. Cohen DJ, Dorr DA, Knierim K, et al. Primary care practices' abilities and challenges in using electronic health record data for quality improvement. Health Aff (Millwood). 2018;37(4):635-643. 10.1377/hlthaff.2017.1254

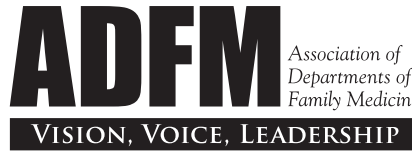

From the Association of Departments of Family Medicine

\section{f A E M D D Prom the Association of Family Medicine Residency Directors Residency Directors}

\section{: $\mathbf{N A P C R G}_{\text {from Napreg }}$}

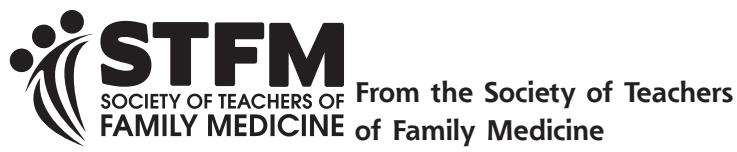

Ann Fam Med 2022;20:95-98. https://doi.org/10.1370/afm.2784.

\section{FROM ADFM, AFMRD, NAPCRG, \& STFM: CAFM SETS GOALS FOR DIVERSITY OF LEADERS \& FACULTY}

A diverse workforce is critical to meeting the diverse needs of our patients. Time and again, we have seen that patients get better care from physicians who look like them, in terms of satisfaction with care, health outcomes and health system usage and expenditures. ${ }^{1-5} \mathrm{We}$ also know that both the family medicine workforce and the family medicine academic workforce (faculty) do not yet reflect the demographic profile of the population of our country. ${ }^{6,7}$ To help increase the diversity of our overall workforce, we must affect change throughout the continuum of medical education, so that students see a career path in medicine by seeing mentors who look like them and career pathway options, including leadership positions. In 2016 the Council of Academic Family Medicine (CAFM) created a Leadership Development Task Force to address the lack of diversity in academic family medicine leadership, including outlining some of these pathways to leadership for underrepresented minorities and women. ${ }^{8}$

As follow-up to one of the recommendations set out by this Leadership Development Task Force ${ }^{9}$ in the March 2021 issue of the Annals of Family Medicine, CAFM shared a baseline set of demographics for the membership of the 4 CAFM organizations along with context for tracking and sharing 